\title{
La jurisdicción especial de paz: la justicia de la esperanza
}

\section{The special jurisdiction of peace: the justice of hope}

\author{
Rosembert Ariza Santamaría*
}

Fecha de recepción: 17 de agosto de 2007

Fecha de aprobación: 12 de septiembre de 2007

\section{Resumen}

Este Artículo se propone socializar los avances de investigación respecto al objetivo específico de la investigación "Reconocer la particularidad y singularidad de la Jurisdicción Especial de Paz frente a la administración formal de justicia". Así, plantea la relación de la Jurisdicción Especial de Paz (JEP) con la justicia ordinaria, estableciendo las diferencias y similitudes existentes para identificar los elementos que hacen particular a la JEP, instaurada en la Constitución Política de 1991 y regulada por la Ley 497 de 1999. Lo anterior se logra a partir de un marco referencial, en el cual se inscribe el surgimiento de la justicia de paz en Colombia, así como en el planteamiento de los debates teóricos existentes con relación al binomio jurisdicción especial-justicia formal, contrastados con las percepciones de jueces de paz, para esbozar finalmente las consecuencias que generan las disyuntivas teóricas en torno al tema.

\section{Palabras clave}

Jurisdicción Especial de Paz, justicia ordinaria, administración de justicia, juez de paz, singularidad.

Abogado. Docente-investigador de la Facultad de Derecho de la Universidad Santo Tomás y coordinador de la Investigación La jurisdicción especial de paz en Colombia: iun nuevo paradigma jurídico?, que se desarrolla actualmente en la línea de investigación de la Facultad, Derecho y Sociedad, de la cual este artículo constituye un avance. El equipo de investigación se encuentra conformado por la abogada investigadora Diana Carolina Abondano Lozano y los estudiantes Lilibeth Lozada Rozo, Laura Zaldúa Contreras y David Peñuela Ortiz. 


\begin{abstract}
This paper has as it main goal to socialize the research advancements with respect to the specific objective of the investigation "Recognize the Peace Special Jurisdiction's particularities and singularities in relation to the Justice formal administration". This, it states the relation between the Peace Special Jurisdiction and the ordinary justice, establishing the existing differences and similarities and identifying the elements that make this Jurisdiction, implemented in the 1991 Political Constitution of Colombia and regulated by the Law 497 of 1999, a particular one. The above is accomplished through a reference framework in which the appearance of the Peace justice in Colombia is inscribed, as well as the set up of current theoretical debates in relation to the pairing special jurisdiction-formal justice, in contrast with the peace judges' perceptions to finally lay out the consequences that originate theoretical disjunctives around this topic.
\end{abstract}

\title{
Key words
}

Special Jurisdiction of Peace, ordinary justice, justice administration judge of the peace, singularity.

\section{PRESENTACIÓN}

\author{
Vivimos revolcaos en un merengue \\ y en un mismo lodo todos manoseaos \\ [...] \\ Igual que en la vidriera irrespetuosa \\ de los cambalaches, \\ se ha mezclao la vida, \\ y herida por un sable sin remaches \\ ves llorar la Biblia contra un calefón \\ Enrique Santos Discépolo
}

La Jurisdicción Especial de Paz (JEP) tiene una vida y desarrollo institucionales bastante recientes. Se encuentra dentro de la estructura de la Rama Judicial del Poder Público y denota elementos y características fundamentales que la diferencian de la administración formal de justicia, como la decisión de los asuntos con criterios de equidad y la elección popular de sus actores (jueces de paz y de reconsideración), con el objetivo de construir convivencia pacífica y lograr el tratamiento integral y pacífico de los conflictos, entre otros (Ley 497 de 1999, Art. 8).
La Jurisdicción Especial de Paz representa elementos institucionales, sociales y culturales claramente diferenciados legalmente; tiene legitimidad propia y características que sobrepasan los cánones formales de la administración de justicia. Sin embargo, ésta toma elementos formales del Derecho y aplica procedimientos que en alguna medida podrían contribuir a perpetuar el discurso jurídico. Aun siendo una justicia basada en parámetros de equidad, los avances de esta jurisdicción en Colombia hacen improbable formas de resistencia al lenguaje dominante de los juristas. Vistas igualmente desde otra perspectiva, estas prácticas constituyen un capital jurídico que genera un nuevo campo, no claramente establecido todavía, pero propiciador de nuevas racionalidades jurídicas y una manera social de regulación desde estos actores sociales. De esta manera, resulta difícil reconocer a qué le aporta finalmente esta jurisdicción y qué acumulado se está haciendo para el mundo jurídico.

A continuación se presenta un avance de la investigación institucional denominada "La jurisdicción especial de paz en Colombia: ¿un nuevo paradig- 
ma jurídico?", en el acápite referente a "Reconocer la particularidad y singularidad de la Jurisdicción Especial de Paz frente a la administración formal de justicia".

En relación con la caracterización de las prácticas sociales de justicia de la Jurisdicción Especial objeto de estudio, debe decirse que no existen en el panorama académico investigaciones o trabajos publicados que aborden el tema de esta manera. Así, el siguiente Artículo contiene un marco referencial sobre la justicia de paz, aborda algunos de los debates existentes en torno a la jurisdicción como tal y esboza ciertos hallazgos del proceso investigativo.

\section{MARCO REFERENCIAL DE LA JUSTICIA DE PAZ}

El origen y desarrollo de la Justicia de Paz ha obedecido a distintos factores sociales y políticos, de acuerdo con la crisis propia de las sociedades donde se ha implementado o se encuentra establecida. Sin embargo, subyace como característica común el ánimo de acercar más la administración de justicia a los ciudadanos ${ }^{1}$, en aras de la resolución pronta y concertada de las diferencias. A continuación se presentan las experiencias de Italia, España y Portugal, en Europa, y de Perú, Venezuela y Colombia, en América Latina.

\section{Europa}

\section{Italia}

La figura del juez de paz fue prevista por la Ley 374 de 1991. Efectivamente comenzó a funcionar

1 “En los países andinos ejercer otras formas de administrar justicia en la que esté presente la comunidad, constituye muchas veces el único medio para que amplios sectores de la población puedan hacer valer sus Derechos". En: Wilfredo Ardito, Norma Gálvez y Jaime Vintimilla (editores), Justicia en los Andes, Boletín de la Red Andina de Justicia de Paz y Justicia Comunitaria, $N^{\circ} 5$ (agosto de 2003), p. 1. a principios de 1993, con el objetivo de facilitar a los ciudadanos la pronta solución de los conflictos civiles y penales de menor complejidad (Pedroso y Trincâo, 2003), Mediante la Ley 468 de 1999, le fueron atribuidas más competencias en materia penal.

El juez de paz tiene como perfil ser un magistrado honorario, no tener carrera como el juez togado, ser seleccionado entre personas con conocimientos básicos de la ley, en problemas de la administración de justicia y experiencia teórico-práctica en cuestiones jurídicas, para desarrollar su labor durante cuatro años. Es nombrado mediante decreto por el Presidente de la República, previa deliberación del Consejo Superior de la Magistratura (Ibíd.: 203). Para optar por el cargo se requiere ser ciudadano italiano, hablar el idioma nativo, no estar privado de los derechos civiles y políticos, ser licenciado en Derecho, tener residencia en el área jurisdiccional donde exista un juzgado de paz y encontrarse admitido mediante un examen de profesión forense.

De acuerdo con la labor que han desempeñado y el cúmulo de procesos ordinarios que han tramitado -reflejado en la descongestión de la justicia civil-, los jueces de paz se consideran fundamentales para la realización efectiva de la justicia, por lo cual se pretende cualificarlos como jueces de equidad o de conciliación.

La actuación del juez de paz se asimila a la del mediador, quien trabaja para lograr un acuerdo entre las partes involucradas, a fin de no tener que acudir a la acción judicial. Los ciudadanos pueden recurrir al juez sin asistencia de abogado y los servicios son gratuitos.

En materia penal, los jueces de paz poseen competencias en delitos previstos por el Código Penal y leyes especiales: asaltos, amenazas e injurias. Asimismo, tienen la posibilidad de elegir actuar en forma conciliatoria/mediadora, puramente 
mediadora o punitiva, frente al crimen (Pedroso y Trincâo, 2003: 206).

\section{España}

La Justicia de Paz tuvo origen en el Artículo 282 de la Constitución de 1812, acuerdo con el cual el presidente de la Cámara de cada población ejercía funciones de conciliación y permitía que quien pretendiese demandar por negocios civiles y por injurias debía presentarse ante él con esa finalidad (Ibíd.: 200). En esta época no existía separación en las funciones del poder judicial y ejecutivo, ni un modelo preciso de justicia de paz, por lo que reformas relativas a la figura del juez de paz, su designación y determinación de competencias, entre otras, se sucedieron de manera fluctuante y crítica.

La Ley Orgánica del Poder Judicial de 1985 consagra como criterios de regulación de los juzgados de paz, principalmente los siguientes: existencia de un juzgado en cada municipio ${ }^{2}$, consideración del juez como lego en Derecho (también puede ser nombrada una persona licenciada en Derecho), designación y nombramiento temporal de los jueces de paz con intervención de los ayuntamientos y competencia objetiva limitada (Pedroso y Trincâo, 2003: 200).

En el panorama jurisdiccional se distinguen dos tipos de juzgados de paz: uno, el de las poblaciones pequeñas, en las que el juez posee el título honorífico de inscripción en la Ley Orgánica del Poder Judicial; y dos, el de las poblaciones mayores, donde la labor jurisdiccional del juez es importante y tiene la oportunidad de practicar varios actos de auxilio judicial.

Debido a inconvenientes como la creciente politización de la figura -a causa de la discrecionalidad en el nombramiento y remoción por parte de los

2

2 Siempre que no exista juez de primera instancia o instrucción. ayuntamientos-, la falta de preparación y conocimientos jurídicos de los jueces de paz y la gran cantidad de remisiones efectuadas a funcionarios judiciales, la figura y los jueces de paz han sido blanco de muchas críticas, cuyas voces claman desde reformar profundamente la institución, suprimirla, o profesionalizarla, hasta elegir popularmente a los jueces. Asimismo, existe una fuerte tendencia a que la totalidad de los jueces de paz sean letrados y hagan parte de la carrera judicial.

Sin embargo, también han desempeñado un papel fundamental para la primera instancia, dada su naturaleza de auxilio en la administración de justicia.

\section{Portugal}

La reforma establecida a la Constitución en 1989, institucionalizó "instrumentos y formas de composición no jurisdiccional de los conflictos", cuyas decisiones no podían ser impuestas a los ciudadanos que acudiesen a dicha jurisdicción. Bajo la reforma constitucional de 1997 -Artículo 209, N 2- (Pedroso y Trincâo, 2003: 215) la mencionada disposición fue incluida expresamente, así como la existencia de los juzgados de paz.

Con la Ley 78 de 2001 se reguló la organización, la competencia y el funcionamiento de los juzgados de paz, otorgándoles como misión "permitir la participación cívica de los interesados" y "estimular la justa composición de los litigios por acuerdo de las partes", lo que les sugiere desarrollar una acción pedagógica en su labor bajo los principios de simplicidad, adecuación, informalidad, oralidad y economía procesal.

La competencia de los juzgados en materia civil y penal se presenta por agrupamientos de consejos antiguos, parroquias o agrupaciones de parroquias del mismo consejo. Sus servicios no son gratuitos y se encuentran sujetos al régimen de apoyo judicial a los ciudadanos (Pedroso y Trincâo, 2003: 215). 
Los jueces de paz requieren, para ser elegidos por concurso público mediante una evaluación y pruebas técnicas, ser de nacionalidad portuguesa, ser licenciado en Derecho, tener goce pleno de derechos civiles y políticos, tener 30 años o más y no haber sido condenado ni acusado por delitos dolosos. El juez de paz cumple en principio una labor conciliadora, pudiendo decidir con base en criterios de equidad, si las partes así lo aceptan.

En el balance realizado sobre los proyectos experimentales de implementación de juzgados de paz en los municipios de Lisboa, Oliveira do Bairro, Seixas y Vila Nova de Gaia, el Consejo de Acompañamiento de la Creación e Instalación de los mismos determinó como problemas en su funcionamiento: el escaso número de juzgados de paz, las limitadas competencias y áreas territoriales. De igual forma, señaló que la recepción por parte de los ciudadanos es positiva, siendo un mes el tiempo promedio de duración de un proceso (Pedroso y Trincâo, 2003: 218)

\section{América Latina}

Perú

La extensa trayectoria histórica y jurídica de la institución de la Justicia de Paz en la vida republicana de este país lo ubica como un referente obligado, no solo en el ámbito regional sino mundial. Así, la figura del juez de paz ha sido prevista en todas las Constituciones, inspirada en la Carta de Cádiz de 1812 (Lovatón Palacios, 2000), que adjudicaba al alcalde el oficio de conciliador y establecía como requisito para acudir a la acción judicial recurrir a esta vía de solución. La Constitución de 1823 acogió dichas características, pero trasladó la función de conciliador al juez de paz, respondiendo así al principio de separación de poderes, lo que suponía una ubicación real ${ }^{3}$ de la Justicia de Paz en la

3 Se dice real, pues formalmente la Justicia de Paz se encontraba ubicada constitucionalmente dentro del poder judicial. estructura formal del poder judicial. Sin embargo, durante la mayor parte del siglo XX, estuvo vinculada al poder local de los alcaldes o prefectos a través de los mecanismos de selección y nombramiento. Se inicia un proceso de discusión provocado por el poder judicial para vincular la justicia de paz al sistema general de justicia.

De acuerdo con Lovatón, en la historia de la Justicia de Paz peruana se distinguen dos épocas en cuanto a la caracterización del Juez: Durante el siglo XIX y parte del XX, este cargo era ejercido por los "notables" de la ciudad, y en el campo por lo terratenientes 0 gamonales ${ }^{4}$. A partir de la segunda mitad del siglo XX, a causa de procesos de reforma agraria, migración y violencia política, entre otros, la labor de juez de paz fue asumida por campesinos, profesores, pensionados y empleados. Este periodo corresponde al actual y se le ha llamado de "jueces populares".

En la Constitución de 1993 la Justicia de Paz se encuentra consagrada en el Artículo 152, incorporando como elemento nuevo la elección popular de los jueces con base en la tradición de diversas comunidades nativas de la región altoandina del país, de elegir democráticamente en asamblea a sus autoridades locales. Este Artículo previó la reserva de ley para la materia, en aras de que la misma regule lo relativo a su funcionamiento, competencias, requerimientos, etc.

La ley aún no ha sido expedida, pero en 1999 la Comisión Ejecutiva del Poder Judicial, que dirige la reforma a la justicia mediante resoluciones administrativas, reguló transitoriamente la elección popular de los jueces, lo que resulta inconstitucional, toda vez que viola la reserva legal advertida.

Respecto al marco legal, la producción de leyes y reglamentos relativos a la justicia de paz ha sido profusa, lo cual hace complejo el panorama de las

4 Esta época se denominó de "jueces propietarios". 
competencias, requisitos, prerrogativas y diversos aspectos de la Justicia de Paz, así como el control de legalidad que pueda desplegar el poder judicial para su desempeño (Lovatón: 2000: 21).

Los juzgados de paz que se encuentran facultados constitucionalmente para administrar justicia y constituyen un nivel especial dentro de la estructura de la administración de justicia. La elección de los jueces, cuyas competencias se ubican en materia civil y penal, se da de dos formas:

- Por el Presidente de cada una de las Cortes Superiores teniendo en cuenta las ternas presentadas por las organizaciones de base, en los casos que no haya elección.

- Por elección popular, a través de asamblea.

La justicia de paz en Perú se caracteriza por ser eminentemente conciliadora, gratuita y empírica, buscando la solución efectiva al conflicto (Zegarra Zevallos, 2000), que a través de la intervención de una persona cercana y amigable, como el vecino de la comunidad, se basa en criterios de equidad para administrar justicia.

David Lovatón ha sugerido algunas fortalezas del modelo peruano, que pueden servir para las experiencias de la región:

- Conveniencia de que la Justicia de Paz forme parte del poder judicial.

- Legitimidad social de la Justicia de Paz.

- Carácter lego de la Justicia de Paz.

A pesar de los resultados y la incidencia social de la figura, aún subsiste en el país una actitud ambivalente frente a la misma por parte del poder judicial, toda vez que por un lado valora, enaltece y reconoce la importancia del trabajo de los jueces de paz, y por otro, no destina los recursos suficientes ni ha establecido una política judicial de largo plazo (Lovatón Palacios, 2000: 30). De igual forma, muchos menosprecian esta justicia y la denominan "de poca monta".

\section{Venezuela}

El primer antecedente de la justicia de paz en Venezuela se remonta a la Constitución de 1819, que otorgaba a la figura responsabilidades de decisión por conciliación y equidad (Ponce Silén, 2000: 60). Sin embargo, a raíz de la implantación de una estructura judicial centralizada en 1945 , desaparecieron los juzgados locales, incluidos los de Paz.

La sociedad venezolana no escapó a la crisis del sistema judicial debido a la ineficiencia y retardo en la resolución de las controversias. En esta crisis resurge la Justicia de Paz junto con los métodos alternativos de resolución de conflictos. Luego de ingentes esfuerzos en cabeza del Consorcio Justicia, y varios rechazos para la aprobación de la ley de la Justicia de Paz en el marco de la reforma judicial, fue aprobada a finales de 1994 la Ley Orgánica de Tribunales y Procedimientos de Paz, que infortunadamente no entró en vigor, pues poco tiempo después fue derogada.

Este acontecimiento motivó el impulso de un nuevo proceso legislativo que dio como resultado la expedición de la Ley Orgánica de la Justicia de Paz, en diciembre de 1995, basada en principios de elección directa de una persona que forme parte de la comunidad y que sea elegida popularmente para que resuelva conflictos, valiéndose de la conciliación y la equidad (Ponce Silén, 1999).

La implementación de la justicia de paz se ha presentado de manera progresiva, debido a que el apoyo gubernamental ha sido mínimo. Sin embargo, la figura ha tenido buena aceptación por parte de la comunidad que presenta, en mayor 
proporción, conflictos de carácter familiar y vecinal (Ibíd.: 65).

La Ley Orgánica como marco jurídico que establece la organización y el desarrollo de la Justicia de Paz otorgó como propósito fundamental al juez de paz, lograr la justicia del caso concreto y garantizar la convivencia pacífica de los miembros de la comunidad vecinal de manera gratuita y expedita (Ibíd.: 63).

Son requisitos para ser juez de paz: "ser una persona de reconocida seriedad laboral, trayectoria moral, sensibilidad social y responsabilidad conocida en su ámbito familiar y local, así como de comprobada sensatez, capacidad para el diálogo y ser respetuoso de la condición humana de sus semejantes" (Ibíd.: 69).

En lo relacionado con la elección y competencia del Juez de Paz, la ley estableció que fuera en circunscripciones intramunicipales de menos de 4.000 habitantes, para un período de tres años con posibilidad de ser reelegidos.

La Constitución Nacional de 1999, en el Artículo 258 , concedió rango constitucional a la justicia de paz, así: "La ley organizará la justicia de paz en las comunidades. Los jueces y las juezas de paz serán elegidos por votación universal, directa y secreta, conforme a la ley".

\section{LA JURISDICCIÓN ESPECIAL DE PAZ EN COLOMBIA}

La Jurisdicción Especial de Paz fue establecida por la Constitución Política, en el Artículo 247, de acuerdo con la decisión unánime de la Comisión Cuarta estatutaria de la Asamblea Nacional Constituyente de acoger la creación de esta figura. En principio sus actores fueron denominados Jueces de Paz y Convivencia, atribuyéndoseles como perfil ser "auténticos funcionarios populares que administran justicia", caracterizados por tener origen popular, ser elegidos de la misma manera, tener respetabilidad en la comunidad y fallar en equidad sin formulismos institucionales preestablecidos (Torres Cárdenas y Ariza Santamaría 2003: 1). El antecedente regional sobre la justicia de paz se encontraba en el Perú.

Entre de las motivaciones que posibilitaron la consagración constitucional de esta jurisdicción especial, se encuentra la necesidad de garantizar a los ciudadanos una solución ágil a sus conflictos: "Sin duda, los Jueces de Paz serán cada vez más útiles para resolver de manera pronta y eficaz conflictos individuales o colectivos de la ciudadanía" (Gaceta Constitucional, 1991: 4), lo cual señala que en principio fue planteada como una vía para la resolución expedita de conflictos, pero articulada a un esfuerzo por construir convivencia pacífica (Torres Cárdenas y Ariza Santamaría 2003: 1).

Los actores de la Jurisdicción Especial de Paz son líderes comunitarios poseedores de cualidades humanas y sensibilidad social y comunitaria, ciudadanos en ejercicio postulados por organizaciones comunitarias con personería jurídica o grupos organizados de vecinos para ser elegidos popularmente, tienen la facultad de administrar justicia basados en la equidad o justo comunitario y no en la ley escrita preestablecida. En este sentido, María Elena Guerra afirma: “Los Jueces de Paz son independientes y las decisiones que toman son en equidad, según los criterios de justicia de la comunidad" (Guerra, 2005: 208).

Estos jueces pertenecen a la rama judicial del poder público y están regidos por los principios que la orientan (Torres Cárdenas y Ariza Santamaría 2003). Sin embargo, se han establecido como principios propios de la jurisdicción la eficiencia, la equidad, la oralidad, la autonomía y la independencia, gratuidad y garantía de los derechos.

La Ley 497 de 1997 creó los Jueces de Paz, reglamentó su organización y funcionamiento, y 
determinó como objeto de la Jurisdicción: “lograr el tratamiento integral y pacífico de los conflictos comunitarios o particulares que voluntariamente se sometan a su conocimiento" (Ley 497 de 1999, Art. 8). Dichos conflictos deben ser susceptibles de transacción, conciliación o desistimiento, no estar sujetos a solemnidades legales y no superar la cuantía de cien salarios mínimos legales mensuales vigentes.

Sobre la naturaleza jurídica de la institución de los jueces de paz, la Corte Constitucional colombiana, en Sentencia C-536 de 1995 (MP: Vladimiro Naranjo Mesa), expresó:

\begin{abstract}
se inscribe dentro del concepto de democracia participativa, al permitir la intervención del ciudadano en el cumplimiento de funciones del Estado, como lo es, en este caso, la judicial. Por otra parte, esta institución guarda también relación con algunos de los deberes que la Constitución consagra a cargo de la persona y del ciudadano, concretamente los de "propender al logro y mantenimiento de la paz" y el de "colaborar para el buen funcionamiento de la administración de justicia".
\end{abstract}

El Juez de Paz es, ante todo, un conciliador, por lo que en una primera etapa intenta que las partes solucionen directamente la controversia y lleguen a un acuerdo satisfactorio. En caso contrario, o de lograr un acuerdo parcial, debe resolver a través de una sentencia o fallo en equidad. Cuando alguna de las partes no se encuentra conforme con la decisión adoptada por el Juez de Paz, puede recurrir al Juez de Paz de Reconsideración, encargado de revisar la sentencia y confirmarla, o modificarla, según el caso.

\section{JUEZ Y JURISDICCIÓN}

A continuación, se retoman tres debates teóricos relevantes existentes en la relación juez de paz-jurisdicción, que aportan diversos elementos en aras de tratar de establecer las características que singularizan la Jurisdicción Especial de Paz en Colombia, la cual -sin lugar a dudas- se encuentra, con la justicia ordinaria o formal, pero dista mucho en la práctica y en el fundamento sustantivo de actuación.

\section{La justicia de paz es un modo de producción de justicia subordinada ${ }^{5}$}

Entendiendo por justicia subordinada aquella heterónoma o que es adjudicada por otro, esta tesis es defendida por Alberto Ceballos Velásquez ${ }^{6}$, quien sostiene que "los rasgos esenciales del juez de paz, en cuanto juez, son los mismos del juez permanente del Estado y el escenario donde se mueve también es un proceso jurisdiccional".

El proceso ante el juez de paz es un proceso jurisdiccional que se ajusta a la noción originaria de esta forma de proceso que delinea con suficiencia el profesor Alvarado Velloso: "Lo que muestra tal concepto, entonces, es la existencia de un fenómeno que no se repite en todo el campo del Derecho: supone lógica y esencialmente la presencia contemporánea de tres sujetos determinados" (Alvarado Velloso, 1989, citado en Ceballos Velásquez, 2000: 192).

"Uno de tales sujetos es, tiene que ser, imparcial, y no puede serlo de otra manera; si no lo es el proceso pierde su naturaleza y se subvierte en un instrumento de opresión y de arbitrariedad. De otro lado, los otros dos sujetos, las partes, deben ser iguales; si no lo fueren, se disuelve la función pacificadora del proceso y se transforma en un escenario de guerra regulada, que concede el favor del triunfo a la parte más fuerte.

\footnotetext{
$5 \quad$ Basado en Ceballos Velásquez, Alberto (2000), “Jueces de Paz. La experiencia en Colombia, una experiencia futura (que está por venir)", En: Corporación Región, Red de Justicia Comunitaria e Instituto Popular de Capacitación (editores), Justicia comunitaria y Jueces de Paz. Las técnicas de la paciencia, $1^{\text {a }}$ ed., Medellín.

6 Magistrado Sala Administrativa, Consejo Seccional de la Judicatura de Antioquia.
} 
El punto límite que permite distinguir la decisión arbitraria de la decisión legítima es el atributo de la imparcialidad del juez.

Quien con su decisión unilateral injiere de modo definitivo en los intereses de otros es, sin lugar a dudas, un juez. Ese designio exige inexorablemente la calidad de imparcial. Si alguien no es sustancialmente imparcial, será lo contrario: será parte, y parece que no existe argumento razonable que justifique que una persona se someta obligatoriamente a los dictados de su contraparte. Juez e imparcialidad son nociones inescindibles.

La Ley 497 de 1999 opta por el sistema de elección popular de los jueces de paz, modalidad que busca dar legitimación democrática-comunitaria a los jueces, de modo tal que ejerza la función aquel que la comunidad reconoce como uno de los suyos. Busca desplazar la idea del juez ajeno y distante en favor del concepto del juez nuestro.

Agrega el magistrado del Consejo Seccional de la Judicatura de Antioquia que la jurisdicción de paz tiene algunos elementos que son problemáticos:

- "La noción de líder de la comunidad, por ejemplo, porque la condición de líder se consagra en el ejercicio de actividades que reclaman vívidas posturas parciales que comprometen la calidad de sujeto imparcial propia del juez. La historia del líder, de pronto, no se acompasa con la historia del juez.

- "Las pequeñas comunidades, por ejemplo el vecindario y la familia, son terrenos propensos al ejercicio caprichoso del liderazgo y de la autoridad. La justicia de paz no puede ser un instrumento para legitimar el uso arbitrario de los poderes de influencia social, sino un mecanismo para racionalizar y democratizar el ejercicio del poder de decidir por vía de autoridad los conflictos intersubjetivos. La intromisión arbitraria en la esfera jurídica de los ciudadanos no resulta más tolerable cuando procede de los líderes de la comunidad que en los demás casos.

- $\quad$ "El origen electoral del juez de paz lo puede vincular con el juego que impone el régimen de mayorías en detrimento del principio de autonomía (contramayorías) que se exige de la función judicial, pues el juez es, por sobre todo, un guardián de las garantías fundamentales de las personas, muy especialmente de las minorías.

"El universo relevante para el Derecho es el de la conducta interferida, el de los comportamientos humanos que trascienden de la esfera de un individuo a la del otro. Y para que tal conducta pueda ser percibida por el otro, debe tener una forma, una manera de exteriorizarse, porque lo que no tiene forma no es relevante para el Derecho porque no hace parte del mundo externo. La forma es un elemento propio del Derecho" (Ceballos Velásquez, 2000: 194).

"La forma en el proceso cumple, entre otras, una importante función legitimadora que democratiza el acto de autoridad: permite la participación del justiciable en el proceso de construcción heterónoma de una norma jurídica subjetiva que regula sus propios intereses. Las reglas de juego, si son claras y simples, garantizan la bilateralidad de la audiencia: permiten que el ciudadano sea copartícipe del proceso encaminado a la solución de su conflicto" (Ceballos Velásquez, 2000: 195).

“El fallo en sí, desligado de su fuente de producción, no es democrático porque, percibido aisladamente, es un acto de autoridad, de origen unilateral; pero si el proceso promueve y garantiza la presencia actuante de los destinatarios de la sentencia en los momentos diferentes al de la emisión del acto de juzgamiento, esta circunstancia confiere a la decisión una legitimación de la que carecería si esta última fuese considerada de 
manera aislada. Dichas así las cosas el proceso ante el juez de paz, si quiere ser expresión de acceso democrático a la justicia, debe ampliar las oportunidades de participación ciudadana; en cada caso la palabra ciudadanos se referirá a los titulares de los intereses que han de ser objeto de regulación en la sentencia".

Para finalizar el autor señala que esta sujeción le impone, por lo menos, el que se impregne de juridicidad básica el manejo de los siguientes aspectos cruciales del proceso ante los jueces de paz:

“En lo procesal. El juez de paz tiene que promover el Derecho fundamental al debido proceso, especialmente lo atinente a la intervención de los justiciables en el proceso, pues la bilateralidad de la audiencia es una expresión del Derecho de participación previsto en el Artículo 40 de la Constitución Política.

"En lo relativo a la competencia. Definir qué es transigible, conciliación y desistible es un ejercicio de averiguación que inevitablemente conduce al universo de lo jurídico.

"En cuanto al cumplimiento de la decisión. La efectividad de la sentencia del juez de paz, es decir, su capacidad para producir un resultado real y práctico en la vida de las personas, está condicionada a un requisito formal: que la parte resolutiva de la decisión, de manera clara y precisa, determine, sin lugar a equívoco alguno, la situación de ventaja reconocida en favor de la parte que obtenga la decisión favorable; y si se impone una obligación, es imprescindible que se especifique el tipo de prestación que se debe y los demás datos que la hagan ejecutable. Este ejercicio, sin lugar a duda, no se puede efectuar sin el auxilio de técnicas propias del Derecho".
Juez y jurisdicción son uno y el mismo concepto o son distintos y distinguibles ${ }^{7}$.

"La primera posición (el juez que se posesiona encarna la jurisdicción de paz) se justifica porque la subjetividad del individuo que deviene juez, se constituye en este escenario y solo mientras ejerce como tal. El actor social (juez) asume el escenario (jurisdicción). Y la jurisdicción la hace él con su acción".

"Existe una simbiosis entre el individuo y el lugar que ocupa en la comunidad. Uno y otro no pueden distinguirse, ni en sus orígenes, ni en sus funciones, ni en sus efectos. Para la otra percepción, la jurisdicción es un campo simbólico destinado a la construcción de trama social. El juez es operador de un mecanismo y asume un papel protagónico en ese campo para facilitar la producción de acumulaciones sociales referidas al saber, a las actitudes y a los valores.

"Aunque esta tensión aparece más en lo teórico que en los promotores de la figura, resulta interesante ahondar en esta reflexión ya que los conceptos producidos por aquellos se vierten en la acción de éstos.

"Así, la primera postura llevaría a que las acciones de los individuos investidos de jueces de paz, frente a los conflictos de los cuales conocen, resulten más importantes o significativas que los sedimentos de saber que quedan en las comunidades.

"La prioridad será entonces la formación de los postulados y, posteriormente, de los jueces de paz.

"La segunda, puede implicar que se concentre la atención en las posibilidades comunitarias de

7 Basado en Torres Cárdenas, César y Ariza Santamaría, Rosembert (2003), "Referentes conceptuales", en: Rosa Ludy Arias Campos y Carmen Lucía Gordillo Guerrero, Sistematización evaluativa de la Jurisdicción de Paz en Colombia, Bogotá, Ministerio de Justicia y del Derecho-Programa de Fortalecimiento y Acceso a la Justicia, p. 9 . 
aprendizaje y construcción de conocimiento y se deje sin importancia la formación en temas legales que, de todas maneras, deberían tener las comunidades y los jueces de paz".

En este punto vale la pena plantear la importancia de que sean los mismos jueces de paz quienes crean y aprehendan que uno de los objetivos o consecuencias de su labor es legitimar la jurisdicción, pues si bien son elegidos popularmente, dicha legitimidad jurisdiccional, obtenida en el ejercicio de su investidura, les otorga un auténtico poder institucional y político que fortalece y empodera esta jurisdicción especial y a ellos mismos como actores sociales que la agencian.

\section{Juez de Paz: ipromotor local de convivencia o juez de la República?}

En el ámbito local, los jueces de paz se tienen que enfrentar desde el día de su posesión, que se realiza ante el alcalde municipal, y los cinco años de ejercicio de su labor, con una barrera en los gobiernos locales, quienes -la mayoría de las veces- los desconocen, ignoran e instrumentalizan.

Usualmente las secretarías de gobierno son el interlocutor de dichos jueces, que en alto porcentaje actúan individualmente y sin sentido de jurisdicción. Este aspecto, explicado anteriormente, se materializa en el ejercicio de la administración de justicia por parte de los jueces, quienes en sus escenarios comunitarios están completamente solos desarrollando su labor. En el mejor de los casos son vistos desde las políticas públicas locales como promotores de convivencia, pero usualmente son signados como un mecanismo alternativo, y por esta vía articulados a espacios institucionales que desconocen la naturaleza jurisdiccional de estos actores sociales.
En este sentido, Francisco Felipe Guevara ${ }^{8}$, a la pregunta: " $¿ Q u e ́$ instituciones han apoyado su labor como Juez de Paz en el ámbito local, municipal, departamental y nacional?", afirma: "En el ámbito municipal, la Alcaldía Municipal de Santiago de Cali creyó en la figura como política pública de convivencia y adelantó el nuevo proceso de elecciones que hace posible que hoy la jurisdicción siga vigente en el municipio de Cali".

En su carácter de "actores voluntarios de convivencia ciudadana" ${ }^{\prime \prime}$ o la nomenclatura con la que cada gobierno los bautice, los jueces de paz son desnaturalizados política y jurídicamente, pues son homologados a otros actores que carecen de la facultad de "fallo" y que están adscritos al poder ejecutivo local. Por este camino terminan enrolados en la justicia de la administración local, la cual -las más de las veces- los autorreferencia con los inspectores de policía.

A esto debemos agregarle las dificultades de la implantación local de la figura, que se desarrolla en tres etapas diferenciadas, compartimentadas y sin conexión ${ }^{10}$, no tanto en la literatura que se dispone frente al tema, como en las acciones que se adelantan o se pretenden adelantar desde el ámbito nacional, se percibe ésta desestructurada y compleja acción.

Para la primera acepción de esta situación, pareciera que cada una de las etapas prescritas en la Ley 497 de 1999 para adelantar la implantación tuviera que ser liderada por un organismo nacional: la primera de difusión y capacitación a la comunidad,

8 Juez de Paz de Reconsideración de Cali (Valle), entrevista realizada el 13 de abril de 2007.

9 Denominación empleada en el Distrito Capital para identificar a mediadores, conciliadores en equidad y a los propios jueces de paz.

10 Véase el plan del Comité Asesor Nacional de la Jurisdicción de Paz 2005 y el documento "Informe de gestión adelantada por la Comisión intersectorial de políticas, divulgación y capacitación comunitaria sobre justicia de paz", en: Ministerio de Justicia y del Derecho-Dirección de Acceso a la Justicia y Fomento a los MASC, Bogotá, agosto de 2002. 
a cargo legalmente del hoy Ministerio del Interior y de Justicia; la segunda, electoral, por el Consejo Nacional Electoral, y la tercera o postelectoral, por el Consejo Superior de la Judicatura.

Así, más allá de lo que se diga o deje de decir, las etapas quedarían inconexas, y sus efectos, impactos y logros se podrían medir sólo en términos procesales: el éxito o fracaso de las mismas solamente se puede afirmar según haya cumplido las actividades que se decidieron para llegar hasta la meta fijada (acuerdo del Concejo Municipal, que fija fecha para realizar el evento electoral, realización de elecciones y capacitar a los jueces elegidos) pero no es visible la incidencia que se tuvo en la transformación de la vida comunitaria.

Se podría decir que la vida municipal o, mejor, los esfuerzos locales para construir y desarrollar esta figura, se ven afectados por la hoy todavía ausente coordinación interinstitucional. Este pecado de origen siempre se refleja más adelante en el desarrollo de la jurisdicción, al implementar procesos nuevos en los diferentes municipios, porque, como ha ocurrido a lo largo de estos años, las experiencias de cada municipio pasan por coordinar el trabajo de instancias legislativas, ejecutivas y de control del respectivo municipio, al tiempo que se apoyan en las producciones 0 capacidades de organismos nacionales.

El trabajo local, entonces, depende más de sus propias condiciones particulares que de lo que se pretenda ordenar, organizar u orientar desde las instancias nacionales.

\section{JURISDICCIÓN ESPECIAL DE PAZ Y JUSTICIA ORDINARIA}

Al poseer el actor comunitario la investidura de juez de la República, hacer parte de la estructura de la rama judicial y tener la posibilidad de emitir fallos con fundamento en la equidad, entre otras razones, se plantea una relación entre la Jurisdicción Especial en comento y la justicia ordinaria. Sin embargo, la JEP reviste elementos especiales que la hacen -en principio- particular frente a la administración formal de justicia, siendo el Juez de Paz y de Reconsideración, el primer autorizado para identificar y caracterizar, a partir de su propia práctica y experiencia, aquellos elementos que constituirían la singularidad de su jurisdicción en relación con la justicia formal u ordinaria.

Bajo esta premisa, se consideró necesario indagar a los Jueces de Paz sobre la característica de la Jurisdicción Especial de Paz respecto de la llamada justicia ordinaria que ellos consideran fundamental, así como las posibles similitudes entre las dos $^{11}$, razón por la que en la sistematización de las entrevistas aplicadas se encontraron opiniones en diversos sentidos. Por una parte, se ubican jueces que privilegian la agilidad del procedimiento establecido en la Ley 497 de 1999, con base en la cual deben actuar, y que se refleja en la solución pronta del conflicto, así: "Lo especial quiere decir que lo que no puede hacer rápido la justicia ordinaria lo podemos hacer los jueces de paz, hay una prontitud, una rapidez..."12. De igual manera la informalidad, destacándose la no necesidad de recurrir a un abogado para hallar fin a la controversia: "...la característica más importante de esta jurisdicción es que por ser una justicia nueva, y alternativa de la justicia común u ordinaria, la norma, la Ley, la 497 le da un procedimiento más sencillo, más ágil... entonces, esa es la importancia, es la diferencia: la agilidad y el procedimiento, oralidad, y no se necesita abogados" ${ }^{\prime 13}$, y la cercanía del Juez de Paz con la comunidad "...informalidad en el sentido de

1 La pregunta base para dicha indagación fue: En su opinión, icuál es la característica más importante de la Jurisdicción Especial de Paz respecto de la llamada justicia ordinaria?

12 En entrevista con Carmen Oliva Macías Franco, Juez de Paz de Cali, 12 de abril de 2007.

13 En entrevista con Luis Ernesto Rojas P., Juez de Paz de Cali, 12 de mayo de 2007. 
que somos jueces de la comunidad, la comunidad nos conoce, hay más informalidad en el trato con nosotros, hay más credibilidad por ser más cercano el Juez de Paz a la misma comunidad y para acceder a nosotros no se necesita una cantidad de empleados, como los jueces ordinarios, que están adelante del Juez haciendo otras funciones, para llegar hasta él, ya en última instancia, sino que de una vez, la informalidad consiste en que el ciudadano tiene un trato directo con el juez de paz"14.

Otros jueces de paz consideran que es la forma para abordar el conflicto dentro de esta jurisdicción especial: "la diferencia para mí es el tratamiento del conflicto y ien qué sentido? En que no solo nosotros pues vemos o nos colocamos ante dos personas que van a conciliar su propio problema y que el resultado de este va a ser de que nosotros, por nuestro intermedio, logremos que esas dos personas que antes habían llegado distanciadas por un problema se vayan con esa característica especial de que puedan volver a ser los amigos que eran antes o la relación que habían tenido anteriormente antes de que los separara el conflicto, entonces eso es algo pues que la justicia ordinaria no hace y que nosotros los Jueces de Paz procuramos en todo sentido que se logre porque son personas que hacen parte de nuestra comunidad, son venidos y nosotros somos de ellos mismos y nos gusta pues que haya la armonía y precisamente la palabra paz, pues creo que debe fundamentarse en este caso en ese sentido: en que las personas hagan la paz y no, pues queden como enemigas, como era antes, porque ante la justicia ordinaria muy posiblemente bajo la ley se puede acabar el conflicto pero no como quedan las personas entre $\mathbf{s i ́}^{\prime \prime 15}$; al igual que la relación con la comunidad, resulta ser su característica esencial:

\footnotetext{
14 En entrevista con Juan Diego Gil M., Juez de Paz de Medellín, 29 de junio de 2007.

15 En entrevista con Navija Navarro, Juez de Paz de Aguazul (Casanare), 13 abril de 2007.
}

"Una de las cosas más importantes es que la justicia de paz va hacia las comunidades, entrevista a los actores, en la justicia ordinaria los actores no van así al Juez porque tienen que hacerlo mediante un sistema de abogado; en la otra va en forma directa, esa es una de las diferenciaciones" ${ }^{\prime 16}$ y "la característica más importante y fundamental de la jurisdicción especial de paz, es la cercanía directa con la comunidad, es conocer de primera mano en un espacio temporal inmediato a los conflictos, porque uno está rodeado de la misma comunidad, los conoce y comparte con ellos"17.

En tanto, para otros jueces resultan primordiales las posibilidades que tiene la justicia de paz al no tener como fundamento de actuación la ley, sino la equidad, tal como se evidencia a continuación: "Para mí la Jurisdicción Especial de Paz va más allá de lo que va la jurisdicción ordinaria; la jurisdicción ordinaria tiene unos parámetros fijados por la ley, por las leyes, nosotros vamos más allá de esas leyes ya que nuestro techo únicamente son los derechos fundamentales y la Constitución Política"18, y "...el juez ordinario defiende la ley, el Juez de Paz va casi en muchos casos en contra de la ley, es decir, la opinión del Juez de Paz es que el salario mínimo es legal pero no justo, desde allí nos encontramos que el uno defiende la ley y el otro defiende la equidad"19.

Con base en lo anterior, se corroboran y revelan características que señalan el camino para la singularización de esta jurisdicción especial. Iniciemos por enunciar las similitudes identificadas:

\footnotetext{
16 En entrevista con Jesús Magín, Juez de Paz de Cali, 12 de mayo de 2007.

17 En entrevista con José Hugo Soler, Juez de Paz de Villavicencio, 13 de abril de 2007.

18 En entrevista con José Dionisio Calderón, Juez de Paz de Bogotá 20 de abril de 2007.

19 En entrevista con Jesús Magín, Juez de Paz de Cali, 12 de mayo de 2007.
} 
- Ambas jurisdicciones son miembros de la rama judicial.

- Tienen capacidad de fallar o emitir sentencia

- Poseen base constitucional y legal.

- Jurisdicción ordinaria y jurisdicción especial de paz tienen el mismo nivel jurisdiccional.

Igualmente se establecieron algunas diferencias de la JEP respecto de la justicia ordinaria:

- Fundamento de las decisiones en la equidad.

- Gratuidad de parte de la jurisdicción de paz.

- Rapidez y eficacia en la solución de los conflictos.

- Relación directa con la comunidad y con las personas.

- Conocimiento de las partes, de su historia y sus vínculos sociales y afectivos.

- Se busca un arreglo o acuerdo que favorezca a los implicados.

- No hay perdedores.

- Se procura esencialmente la recuperación del vínculo social y afectivo.

- Procedimiento ágil y preferentemente oral (ciertamente informal).

- Es ejercida por la propia ciudadanía, por la propia comunidad.

Evidentemente la Jurisdicción Especial de Paz es una justicia rogada, voluntaria y con una enorme capacidad de armonizar la vida comunitaria y propender por un modelo de justicia que no sea el adjudicativo y formalista que tenemos hegemónicamente desde el positivismo jurídico (el llamado formalismo). La singularidad de esta jurisdicción se expresa en su vocación eminentemente social y comunitaria, en la proximidad y cercanía con la vida de los sujetos involucrados en el conflicto $y$, por supuesto, en la rapidez y eficacia que se tiene para solucionar los conflictos, como ya se dijo. Así, el juez de paz se asume como una persona facultada para ayudar a solucionar conflictos (labor jurisdiccional), y como actor social, cuya legitimidad reside en lo comunitario de su actuación (actor comunitario).

A continuación, se recogen ciertas apreciaciones de los jueces sobre este aspecto ${ }^{20}$ : "...que el Juez de Paz es un juez de la República como lo es un juez formal, y sus decisiones también tienen la misma fuerza de un juez formal..." ${ }^{21}$ y "...y de la justicia formal cuando se dicta un fallo, una sentencia, nos parecemos ahí en ese momento a la justicia formal"22. Igualmente resulta claro uno de los puntos en los cuales se encuentran como jurisdicciones que son: "En cuanto a la Justicia Ordinaria, esta (la jurisdicción de paz) tiene similitud en que también debe tener en cuenta la Constitución Nacional y respetar el Derecho al debido proceso" 23 .

Sin embargo, otros jueces opinaron que no podía afirmarse que exista semejanza entre las dos jurisdicciones, con base en los siguientes argumentos: "No encuentro ni una sola similitud, primero porque en la una hay que pagar para que le hagan justicia, esa es una justicia paga, si yo no tengo con qué pagar no me hacen justicia. De pronto en la justicia penal tenemos algunas similitudes porque se escucha a los actores; aquí en esta escuchan a los actores, hacen lo mismo que hacemos los

20 La pregunta realizada fue: ¿qué similitudes encuentra entre las dos jurisdicciones?

21 Julián Aristizábal, op. cit. 20 de abril de 2007.

23 En entrevista con José Hugo Soler, Juez de Paz de Villavicencio, 13 abril de 2007. 
Jueces de Paz, pero en lo demás no porque el juez penal o juez civil, etc., etc. él tiene que aplicar una ley, es decir, defender una ley, lo cual no tiene en cuenta para nada las personas, él defiende la ley, defiende los procedimientos más no tiene en cuenta las personas; la justicia de paz hace lo contrario, desconocemos el procedimiento, desconocemos la ley pero le damos importancia a la per-

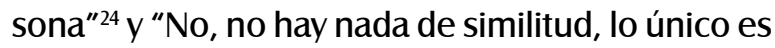
que ambos cumplen con una finalidad, la misma, que es administrar justicia, pero lo que sucede es que en la ordinaria la justicia pocas veces va para el pueblo, en la justicia de paz la justicia va para el pueblo y es del pueblo, y es el pueblo el que decide"$^{\prime 25}$. El fundamento jurídico de las decisiones constituye otra razón: "Yo no le encuentro ningún parecido, es decir, la justicia de paz es totalmente diferente a la justicia ordinaria, la justicia ordinaria se rige prácticamente a las leyes que están escritas y no se salen de las leyes; en cambio, la justicia de paz no, eso se hace acorde a la misma situación, a los problemas que se presentan"26.

\section{La esperanza a la deriva}

Rodrigo Uprimny sostiene que en Colombia el juez de paz es una especie de institución bisagra (Uprimny Yepes, 2000: 65) entre las formas no estatales de resolución de los conflictos y el Derecho estatal. "De un lado, es un juez, es decir, es una autoridad reconocida por el Estado, y como tal tiene algunos poderes coactivos, aunque estos sean mínimos. Es más, conforme a la ley, este juez está sometido a controles disciplinarios por parte del Consejo Superior de la Judicatura, que es el mejor signo de que representa una justicia estatal. Pero, de otro lado, este juez es el más comunitario de los funcionarios oficiales. Así, no

24 En entrevista con Jesús Magín, Juez de Paz de Cali, 12 de mayo de 2007.

25 En entrevista con Luis Ernesto Rojas P., Juez de Paz de Cali, 12 de mayo de 2007.

26 En entrevista a Álvaro Orozco R., Juez de Paz de Nunchía, 12 de abril de 2007. decide aplicando la ley sino en equidad, por lo cual incorpora muchos elementos del Derecho no oficial y de los usos y costumbres locales. Además, este juez, en general, debe buscar la conciliación de las partes, puesto que su función pacificadora le genera esa dinámica. Finalmente, debido a que es electo y que su competencia es voluntariamente dispensada por las partes, sus vínculos con la comunidad son estrechos, pues el juez de paz debe luchar permanentemente por conservar su credibilidad y legitimidad. En efecto, como dice Jaime Giraldo Ángel, para que puedan conocer de un caso, estos jueces son elegidos dos veces por la comunidad. Así, acceden al cargo por elección popular y acceden al caso por designación de las partes.

"Pero lo que es muy interesante es que está entroncado con la justicia estatal, y por ello, la puesta en marcha de los jueces de paz en Colombia puede ser una posibilidad para articular los procesos de movilización comunitaria con los distintos mecanismos formales que hoy existen" (Uprimny Yepes, 2000: 65).

Por su parte, Jesael Antonio Giraldo Castaño -Magistrado del Consejo Superior de la Judicatura- afirma que la jurisdicción especial de paz, "es un verdadero elemento de aproximación entre la comunidad y el Estado, es un eslabón entre la justicia formal y la comunitaria" (Giraldo Castaño, 2007: 46), tesis que en principio podría ser similar a la de Uprimny. No obstante agrega el magistrado que esta jurisdicción "...es todo lo opuesto a la justicia formal. Se procura con ella una justicia creíble, aceptable y confiable, cuyos operadores, los jueces de paz, son elegidos directamente por los destinatarios de sus decisiones. Por ello, el juez con mayor legitimidad en Colombia es el de paz, como el único que es producto de elección popular directa" (Ibíd.: 46).

Igualmente, sostiene que los jueces de paz se sitúan en los mecanismos alternativos de solución 
de conflictos, que la jurisdicción "procura configurarse como un medio de descongestión para la justicia ordinaria y, sobre todo, como solución para los conflictos que día a día se presentan dentro de una comunidad". Esta afirmación nos sitúa en la discusión sobre la calidad de jurisdicción y la de mecanismo alternativo; de si efectivamente los jueces de paz hoy son realmente descongestionadores y por ello son asumidos en algunos municipios como "auxiliares de la justicia", o más común y popularmente denominados tinterillos.

Retomando al magistrado Ceballos, quien considera problemático el rol de líder (juez de paz) de la comunidad, que actúa en pequeñas comunidades donde es altamente vulnerable a un ejercicio caprichoso del liderazgo y de la autoridad. Difiere Ceballos, entonces, de Uprimny y Giraldo, quienes ven en esta su mayor cualidad. Afirma, además, Ceballos, que la justicia de paz no puede ser un instrumento para legitimar el uso arbitrario de los poderes de influencia social, sino un mecanismo para racionalizar y democratizar el ejercicio del poder de decidir por vía de autoridad los conflictos intersubjetivos. El magistrado del Consejo Seccional encuentra, asimismo, problemático el origen electoral del juez de paz, ya que lo puede vincular con el juego que impone el régimen de mayorías, en detrimento del principio de autonomía (contramayorías) que se exige de la función judicial, pues el juez es, por sobre todo, "un guardián de las garantías fundamentales de las personas, muy especialmente de las minorías". Contrario sensu, Jesael Giraldo C. ve en este aspecto, la mayor cualidad de estos operadores.

Finalmente, agregaría la encrucijada local-nacional, que termina de complejizar este análisis, toda vez que los jueces de paz siguen movidos por estos dos niveles de administración estatal con una relación institucional de orden nacional con el poder judicial, y con una dependencia local del ejecutivo.
De todos y de nadie parece ser la responsabilidad institucional de esta jurisdicción. El Ministerio del Interior y de Justicia propone acabar esta figura, sin que conozcamos aún un solo argumento serio. Lo cierto es que estos hombres y mujeres le apuestan a la convivencia y a la solución pacífica de las diferencias, pero están solos... a la deriva.

\section{BIBLIOGRAFÍA}

ARDITO, Wilfredo; GÁLVEZ M., Norma; y VINTIMILLA, Jaime (editores) (2003). Justicia en Ios Andes, Boletín de la Red Andina de Justicia de Paz y Justicia Comunitaria $N^{\circ} 5$, agosto.

ARIAS CAMPOS, Rosa Ludy y GORDILLO GUERRERO, Carmen Lucía (2003). Sistematización evaluativa sobre la Jurisdicción de Paz en Colombia. Bogotá: Ministerio del Interior y Justicia-Programa de Fortalecimiento y Acceso a la Justicia.

CEBALLOS VELÁSQUEZ, Alberto (2000), "Jueces de Paz: La experiencia en Colombia, una experiencia futura (que está por venir)". En: CORPORACIÓN REGIÓN, RED DE JUSTICIA COMUNITARIA E INSTITUTO POPULAR DE CAPACITACIÓN (editores), Justicia Comunitaria y Jueces de Paz. Las técnicas de la paciencia. $1^{\text {a }}$ ed., Medellín.

GACETA CONSTITUCIONAL No. 84, 28 de mayo de 1991, p. 4.

GIRALDO CASTAÑO, Jesael Antonio (2007), "La justicia de paz como un modelo integral". En: Revista Judicial-Eficacia, eficiencia, efectividad y excelencia en la justicia, (marzo). Bogotá: Imprenta Nacional de Colombia.

GUERRA CERRÓN, María Elena (2005). Hacia una Justicia de Paz. Un asunto de interés nacional. $1^{\mathrm{a}}$ ed. Lima: Editora Jurídica Grijley.

LOVATÓN PALACIOS, David (2000), "La Justicia de Paz en el Perú: aspectos positivos y límites". En: 
NORMA GÁLVEZ, M. (editora). Justicia de Paz en la Región Andina. Experiencias comparadas, utopías compartidas. $1^{\text {a }}$ ed., Bogotá: Corporación Excelencia en la Justicia.

PEDROSO, Joâo y Trincâo, Catarina (2003), “El (re) nacimiento de la Justicia de Paz: ¿Una reforma democrática o tecnocrática de la justicia? Las experiencias de Italia, España, Brasil y Portugal", En: EI Otro Derecho, $N^{\circ} 30$, Variaciones sobre la Justicia Comunitaria. Bogotá: Instituto Latinoamericano de Servicios Legales Alternativos (ILSA) y Red de Justicia Comunitaria.

PONCE SILÉN, Carlos Eduardo (2000). “Ley Orgánica de la Justicia de Paz en Venezuela: ilmpulso o freno al desarrollo de la figura?". En: NORMA GÁlVEZ, M. (editora). Justicia de Paz en la Región Andina. Experiencias comparadas, utopías compartidas. $1^{\text {a }}$ ed., Bogotá: Corporación Excelencia en la Justicia.

. 1999. La Justicia de Paz en Venezuela. Disponible en www.idl.org.pe/publicaciones.

TORRES CÁRDENAS, César y ARIZA SANTAMARÍA, Rosembert (2003). Las bases políticas y legales de la Jurisdicción Especial de Paz en Colombia. Mimeo. .y BORRERO GARCÍA, Camilo (2002),

Módulo para formación de Jueces de Paz-Módulo de autoaprendizaje, Bogotá: Escuela Judicial Rodrigo Lara Bonilla, Consejo Superior de la Judicatura y Editorial Unibiblos.

UPRIMNY YEPES, Rodrigo (2000), “ ¿Son posibles los jueces de paz y la justicia comunitaria en contextos violentos y antidemocráticos?". En: Pensamiento Jurídico, Revista de teoría del Derecho y análisis jurídico, $\mathrm{N}^{\circ} 12$. Bogotá: Universidad Nacional de Colombia.

ZEGARRA ZEVALLOS, Orestes (2000), "Breves comentarios sobre la Justicia de Paz en Perú" En: GÁlVEZ M., Norma (editora). Justicia de Paz en la Región Andina-Experiencias comparadas, utopías compartidas. $1^{\text {a }}$ ed., Bogotá: Corporación Excelencia en la Justicia.

\section{LEYES Y JURISPRUDENCIA}

1. LEY 497 de 1999, "Por la cual se crean los jueces de paz y se reglamenta su organización y funcionamiento".

2. CORTE CONSTITUCIONAL, Sentencia C-536 de 1995. MP: Vladimiro Naranjo Mesa. 